\title{
Management of community-acquired pneumonia in children: South African Thoracic Society guidelines (part 3)
}

\author{
G Reubenson, ${ }^{1}$ FCPaed (SA); T Avenant, ${ }^{2}$ FCPaed (SA); D P Moore, ${ }^{3} \mathrm{PhD}$; G Itzikowitz, ${ }^{4} \mathrm{MSc} ;$ S Andronikou, ${ }^{4,5} \mathrm{PhD} ; \mathbf{C}$ Cohen, ${ }^{6} \mathrm{PhD}$; \\ R J Green, ${ }^{2} \mathrm{PhD}$; P Jeena, ${ }^{7}$ FCPaed (SA); R Masekela, ${ }^{7} \mathrm{PhD}$; M P Nicol, ${ }^{8} \mathrm{PhD}$; A Pillay, ${ }^{7}$ Cert ID Paed (SA); S A Madhi, ${ }^{9,10} \mathrm{PhD}$; \\ H J Zar, ${ }^{4,11} \mathrm{PhD}$; A C Argent, ${ }^{4} \mathrm{MD}$ (Paediatrics)
}

\author{
${ }^{1}$ Department of Paediatrics and Child Health, Rahima Moosa Mother and Child Hospital, Faculty of Health Sciences, University of the Witwatersrand, \\ Johannesburg, South Africa \\ ${ }^{2}$ Department of Paediatrics and Child Health, Faculty of Health Sciences, University of Pretoria, South Africa \\ ${ }^{3}$ Department of Paediatrics and Child Health, Chris Hani Baragwanath Academic Hospital, University of the Witwatersrand, Johannesburg, \\ South Africa \\ ${ }^{4}$ Department of Paediatrics and Child Health, Red Cross War Memorial Children's Hospital and Faculty of Health Sciences, \\ University of Cape Town, South Africa \\ ${ }^{5}$ Department of Pediatric Radiology, Perelman School of Medicine, University of Pennsylvania, and Children's Hospital of Philadelphia, PA, USA \\ ${ }^{6}$ Centre for Respiratory Diseases and Meningitis, National Institute for Communicable Diseases, Johannesburg, South Africa \\ Department of Paediatrics and Child Health, Nelson R Mandela School of Medicine, School of Clinical Medicine, College of Health Sciences, \\ University of KwaZulu-Natal, Durban, South Africa \\ ${ }^{8}$ Division of Medical Microbiology, Department of Pathology, Faculty of Health Sciences, University of Cape Town, South Africa; and \\ Division of Infection and Immunity, School of Biomedical Sciences, University of Western Australia, Perth, Australia \\ ${ }^{9}$ South African Medical Research Council Vaccine and Infectious Diseases Analytics Unit, University of the Witwatersrand, Johannesburg, \\ South Africa \\ ${ }^{10}$ Department of Science and Technology/National Research Foundation: South African Research Chair in Vaccine Preventable Diseases, \\ Faculty of Health Sciences, University of the Witwatersrand, Johannesburg, South Africa \\ ${ }^{11}$ South African Medical Research Council Unit on Child and Adolescent Health, University of Cape Town, South Africa
}

Corresponding author: G Reubenson (gary.reubenson@wits.ac.za)

Background. Pneumococcal conjugate vaccine (PCV) administration and other advances have been associated with a shift in the aetiological spectrum of community-acquired pneumonia, necessitating reconsideration of empiric antibiotic treatment guidelines. Management strategies have also evolved in the last decade.

Objectives. To produce revised guidelines for the treatment of pneumonia in South African (SA) children, including ambulatory, hospital and intensive care management.

Methods. An expert subgroup, reviewing evidence on the management of childhood pneumonia, was convened as part of a broader group revising SA guidelines. Evidence was graded using the British Thoracic Society (BTS) grading system and recommendations were made. Results. Antibiotic treatment depends on the child's age, possible aetiology, antimicrobial resistance patterns, previous treatment, as well as factors affecting host susceptibility, including HIV, and nutritional and vaccination status. All children with signs of severe pneumonia should receive antibiotics. Children $<1$ month of age with pneumonia should be hospitalised and treated with ampicillin and an aminoglycoside. For treatment of ambulatory children $>1$ month of age, high-dose amoxicillin remains the preferred antibiotic. For severe pneumonia in this age group, hospitalisation and empiric treatment with amoxicillin-clavulanate orally is recommended; if oral therapy is not tolerated, intravenous therapy is recommended. Generally, 5 days of therapy is proposed, but longer duration may be needed in cases of severe or complicated disease. A macrolide antibiotic should be used if pertussis, mycoplasma or chlamydia pneumonia is suspected. Most hypoxic children can receive oxygen via nasal cannulae, but respiratory support should be individualised and extends to non-invasive and invasive ventilation in some cases. Children should be fed enterally; if this is not possible, administer intravenous isotonic fluids at $<80 \%$ of maintenance, with monitoring of sodium levels. Empiric antibiotic treatment is the same in HIV-infected, HIV-exposed uninfected and HIV-uninfected children, although treatment for pneumocystis pneumonia and/or cytomegalovirus pneumonia should be considered in HIV-infected infants, especially in the absence of combination antiretroviral therapy.

Conclusions. Updated guidelines optimise the management of childhood pneumonia in the context of changing epidemiology, improvements in HIV prevention and new evidence on management.

S Afr Med J 2020;110(8):734-740. https://doi.org/10.7196/SAMJ.2020.v110i8.15020

Changes in the epidemiology and aetiology of childhood pneumonia have necessitated a revision of management strategies. Pneumococcal and Haemophilus influenzae type b (Hib) conjugate vaccines have resulted in a shift in bacterial aetiology, with non-typable $H$. influenzae and Staphylococcus aureus causing a greater proportion of radiologically confirmed severe pneumonia in hospitalised children.

Improvements in diagnostic methods have further contributed to recognising causative pathogens. Furthermore, management 
strategies of children with pneumonia continue to evolve and improve.

\section{Treatment of childhood pneumonia Antibiotic treatment}

Choice of empiric antibiotic treatment depends on the child's age, possible aetiology, antimicrobial resistance patterns, previous treatment, as well as factors affecting host susceptibility, including HIV, nutritional and vaccination status. All children with signs of pneumonia or severe pneumonia should receive antibiotics (evidence level Ib). ${ }^{[1,2]}$

\section{Adaptation of guidance to address antibiotic resistance}

Substantial (>80\%) reductions in the incidence of invasive pneumococcal disease were observed within 4 years of pneumococcal conjugate vaccine $(\mathrm{PCV})$ introduction. ${ }^{[3]}$ High-dose amoxicillin is effective against pneumococci with low- and intermediate-level penicillin non-susceptibility causing pneumonia. Empiric therapy for hospitalised children with community-acquired pneumonia (CAP) should cover non-typable $H$. influenzae and S. aureus. ${ }^{[4,5]}$

\section{Which empiric antibiotic?}

For severe pneumonia in children $>1$ month of age, amoxicillinclavulanate $(90 \mathrm{mg} / \mathrm{kg} / \mathrm{day}$ of amoxicillin component) is recommended. Oral therapy ( $45 \mathrm{mg} / \mathrm{kg} /$ day 12 -hourly of amoxicillin component) is preferable, but intravenous therapy $(30 \mathrm{mg} / \mathrm{kg} /$ dose of intravemous amoxicillin component 8-hourly) should be initiated in children who are unable to tolerate oral medications, if there is a concern about oral absorption, or if the child is severely ill.

For children $<1$ month of age, initial therapy should be intravenous ampicillin $(40 \mathrm{mg} / \mathrm{kg} /$ dose 6-hourly) and gentamicin $(7.5 \mathrm{mg} / \mathrm{kg} /$ dose daily) to cover common neonatal pathogens, including Listeria spp. (evidence level II). Group B Streptococcus, S. aureus, Chlamydia trachomatis and viruses should also be considered as causes of neonatal pneumonia. Consideration should be given to broadening cover if there is no clinical improvement within 48 hours of initiation of therapy.

A macrolide should be included when 'atypical' pathogens (e.g. Mycoplasma spp., Chlamydophila spp., pertussis) are suspected (evidence level IVa).

For ambulatory treatment of pneumonia, amoxicillin $(45 \mathrm{mg} / \mathrm{kg} / \mathrm{dose}$ 12-hourly) remains the preferred antibiotic for children $>1$ month old. Outpatient management should not be considered for infants $<1$ month of age (Table 1).

HIV infection or exposure influences investigation and management of children with pneumonia (see below: Special circumstances: HIV infection or exposure).

\section{Route of administration}

Oral therapy is preferable; however, parenteral antibiotics should be used for children requiring intensive care unit (ICU) admission or for those too ill to tolerate oral medication. There are, however, risks and costs associated with intravenous use, and oral de-escalation is recommended as soon as feasible (evidence level IIIa). ${ }^{[6,7]}$

\section{Duration of antimicrobial therapy}

In general, 5 days of antibiotic therapy is recommended, but longer duration may be needed in children with severe or complicated disease, if there is a poor response to therapy, or as informed by microbiology results.

Bacteraemic staphylococcal pneumonia should be treated for $14-28$ days, dependent on complications and response to treatment. ${ }^{[8]}$
Uncomplicated presumed staphylococcal pneumonia (i.e. blood culture negative, but with suggestive clinical or chest X-ray (CXR) features) may be appropriately managed with a 7 - 10-day course of targeted antibiotic therapy, depending on clinical response (evidence level IVa). ${ }^{[9]}$

\section{Management of a child who is not responding to therapy}

A poor response to treatment has many possible explanations. Consider infection with Mycobacterium tuberculosis, viruses, fungi or atypical organisms. Evaluate for the presence of a foreign body, empyema, heart disease or underlying immunodeficiency. ${ }^{[10]}$

Change to amoxicillin-clavulanate if there is a poor clinical response or deterioration in a child treated with amoxicillin. For children initially treated with amoxicillin-clavulanate, change to ceftriaxone (evidence level IVa). ${ }^{[2]}$ Where laboratory support is available, it is strongly recommended to repeat a microbiological work-up, including blood culture, before changing antibiotics.

\section{Summary: Antibiotic therapy for community-acquired pneumonia}

1. Oral amoxicillin is recommended for children $>1$ month of age who do not require hospitalisation (evidence level Ia).

- Treatment duration should be 5 days, with review after 3 days to evaluate response.

- Switch to amoxicillin-clavulanate if there is clinical deterioration, and consider referral for further investigation.

2. Children $<1$ month of age should be hospitalised and treated with ampicillin and an aminoglycoside (evidence level $\mathrm{Ib}$ ).

3. Amoxicillin-clavulanate (intravenously or orally) is recommended for treatment of hospitalised children $>1$ month of age with severe pneumonia (evidence level IVa).

- Treatment duration should be 5 days.

- If there is clinical deterioration, switch to ceftriaxone or cefotaxime for 5 days (evidence level IVa).

4. Treatment duration should be prolonged for severe or complicated disease, and depend on microbiology testing.

- Bacteraemic S. aureus pneumonia may require 14 - 28 days of antibiotic therapy, depending on clinical response (evidence level IVa).

5. Macrolide antibiotics should be used if pertussis, mycoplasma or chlamydia is suspected (evidence level IVa).

\section{Adjunctive therapies}

\section{Antiviral treatment}

Oseltamivir is of limited benefit and is not recommended for routine use. Consider use during the influenza season in children at high risk for severe influenza, who present soon after symptom onset. ${ }^{[8,24-36]}$

\section{Corticosteroid therapy}

The role of corticosteroids remains unclear. They have a role in children with suspected or confirmed pneumocystis pneumonia (PCP) (see below: Special circumstances: HIV infection or exposure - Treatment), or in pulmonary tuberculosis with nodal airway compression and obstruction. ${ }^{[1,12]}$

\section{Vitamin and micronutrient supplementation}

Vitamin A. Vitamin A supplementation reduces severity of respiratory complications of measles, ${ }^{[13]}$ but is not recommended for routine use. ${ }^{[14]}$ Consider routine vitamin A supplementation for HIV-infected or malnourished children with CAP. ${ }^{[15]}$ 
Table 1. Empiric antibiotic therapy

\begin{tabular}{|c|c|c|}
\hline Age & Outpatients & Inpatients \\
\hline $0-1$ month & Children $<1$ month of age should be hospitalised & $\begin{array}{l}\text { Ampicillin } 50 \mathrm{mg} / \mathrm{kg} \text { IV } 6 \text {-hourly, } \\
\text { or benzylpenicillin } 50000 \mathrm{U} / \mathrm{kg} \text { IM/IV } 6 \text {-hourly } \\
\text { and gentamicin } 7.5 \mathrm{mg} / \mathrm{kg} \mathrm{IM} / \mathrm{IV} \text { daily } \\
\text { If poor response } \\
\quad \text { Ceftriaxone } 50 \mathrm{mg} / \mathrm{kg} \text { IV } 12 \text {-hourly } \times 5 \mathrm{~d} \text { or } \\
\text { Cefotaxime } 50 \mathrm{mg} / \mathrm{kg} \text { IV } 8 \text {-hourly } \times 5 \mathrm{~d} \\
\text { If cultures are negative, switch to oral amoxicillin-clavulanate } \\
\text { when clinically improving and taking well orally - complete a } \\
\text { total antibiotic duration of } 5 \mathrm{~d} \\
\text { If cultures are positive, use targeted therapy according to the } \\
\text { organism's susceptibility pattern } \\
\text { Step down to oral antibiotic therapy as soon as the patient is } \\
\text { clinically stable } \\
\text { Add } \\
\quad \text { Azithromycin } 10 \mathrm{mg} / \mathrm{kg} \text { daily orally } \times 5 \mathrm{~d} \text { if Chlamydia } \\
\quad \text { trachomatis is suspected (alternative: clarithromycin } 7.5 \mathrm{mg} / \mathrm{kg} / \mathrm{d} \\
\text { orally } 12 \text {-hourly } \times 5 \mathrm{~d} \text {; erythromycin is contraindicated in this } \\
\text { age group) }\end{array}$ \\
\hline$>1$ month & $\begin{array}{l}\text { Amoxicillin } 45 \mathrm{mg} / \mathrm{kg} / \text { dose } 12 \text {-hourly orally } \times 5 \mathrm{~d} \\
\text { If poor response } \\
\text { Amoxicillin-clavulanate } 45 \mathrm{mg} / \mathrm{kg} / \text { dose } 12 \text {-hourly } \times 5 \mathrm{~d} \\
\text { Add } \\
\quad \text { Azithromycin } 10 \mathrm{mg} / \mathrm{kg} \text { orally daily } \times 5 \mathrm{~d} \\
\text { if } \text { Mycoplasma pneumoniae, Chlamydia pneumoniae or } \\
\text { C. } \text { trachomatis suspected (alternatives: clarithromycin } \\
7.5 \mathrm{mg} / \mathrm{kg} / \mathrm{d} \text { orally every } 12 \mathrm{~h} \text { for } 10 \mathrm{~d} \text { or erythromycin } \\
50 \mathrm{mg} / \mathrm{kg} / \mathrm{d} \text { for } 10-14 \mathrm{~d} \text { ) }\end{array}$ & $\begin{array}{l}\text { Amoxicillin-clavulanate } 30 \mathrm{mg} / \mathrm{kg} / \mathrm{dose} \text { (of amoxicillin } \\
\text { component) } 8 \text {-hourly IV } \times 5 \mathrm{~d} \text { or } \\
\text { Amoxicillin-clavulanate } 45 \mathrm{mg} / \mathrm{kg} / \text { dose orally } 12 \text {-hourly } \times 5 \mathrm{~d} \\
\text { If cultures are positive, use targeted therapy according to the } \\
\text { organism's susceptibility pattern } \\
\text { Step down to oral antibiotic therapy as soon as the patient is } \\
\text { clinically stable } \\
\text { For susceptible Staphylococcus aureus, use } \\
\text { flucloxacillin } 50 \mathrm{mg} / \mathrm{kg} \text { orally } 6 \text {-hourly } \times 2-4 \text { weeks } \\
\text { If poor response } \\
\text { Ceftriaxone } 50 \mathrm{mg} / \mathrm{kg} \text { IV } 12 \text {-hourly } \times 5 \mathrm{~d} \text { or } \\
\text { Cefotaxime } 50 \mathrm{mg} / \mathrm{kg} \mathrm{IV} 8 \text {-hourly } \times 5 \mathrm{~d} \\
\text { Add } \\
\text { Vancomycin } 10-20 \mathrm{mg} / \mathrm{kg} / \text { dose } 6 \text {-hourly or } \\
\text { Clindamycin for suspected CA-MRSA } 1 \text { month - } 16 \text { years: } \\
20 \text { - } 40 \mathrm{mg} / \mathrm{kg} \text { IV or IM/d, in } 3 \text { - } 4 \text { equally divided doses } \\
\text { Use higher doses for treatment of more severe infections } \\
\text { Add } \\
\text { Azithromycin } 10 \mathrm{mg} / \mathrm{kg} \text { orally daily } \times 5 \mathrm{~d} \text { if } M \text {. pneumoniae, } \\
\text { C. pneumoniae or C. trachomatis suspected (alternative: } \\
\text { clarithromycin or erythromycin) }\end{array}$ \\
\hline
\end{tabular}

Vitamin D. Vitamin D supplementation does not appear to improve CAP outcomes and is not routinely recommended (evidence level Ia). ${ }^{[16-19]}$

\section{Summary: Adjuvant therapies}

1. Oseltamivir should be considered as early empiric therapy in children at risk of severe influenza-related pneumonia, who are hospitalised during the influenza season (evidence level II).

2. Routine use of corticosteroids for childhood CAP is discouraged (evidence level Ib).

3. Vitamin A is indicated for measles-associated pneumonia, or in those with vitamin A deficiency (evidence level Ib).

4. Do not routinely use vitamin D supplementation (evidence level Ia).

When can a hospitalised child be discharged?

Apyrexial children no longer requiring oxygen, with adequate oral intake and acceptable home circumstances, can generally be safely discharged (Table 2). ${ }^{[20]}$

\section{General and supportive measures Oxygen therapy}

Assess oxygenation with regular pulse oximetry. If $<92 \%$ at sea level (or $<90 \%$ at altitude $\geq 1800 \mathrm{~m}$ ), administer oxygen via nasal cannula or face mask to maintain oxygen saturation $92-94 \%$ (evidence level II) ${ }^{[21]}$ If pulse oximetry is unavailable, administer oxygen if there is central cyanosis, grunting, restlessness, inability to drink or feed, or if respiratory rate is $\geq 70 /$ breaths per minute. ${ }^{[22]}$

\section{Respiratory support}

High-flow humidified nasal oxygen (HFHNO) or nasal continuous positive airway pressure (nCPAP) systems provide support to children with severe respiratory disease (see below: Care of the child 
with pneumonia in the paediatric ICU or high care). ${ }^{[23,24]}$ These can be safely provided in adequately staffed and equipped high-care areas and district hospitals. ${ }^{[24,25]}$

\section{Blood transfusion}

In general, children who are haemodynamically stable should not be transfused if the haemoglobin $(\mathrm{Hb})$ level is $\geq 7 \mathrm{~g} / \mathrm{dL}$ (evidence level $\mathrm{Ib}$ ); if their $\mathrm{Hb}$ is $<5 \mathrm{~g} / \mathrm{dL}$, then transfuse packed red cells to raise the $\mathrm{Hb}$ to above the transfusion threshold (i.e. not to 'normal ranges') (evidence level II). For children with $\mathrm{Hb} 5$ - $7 \mathrm{~g} / \mathrm{dL}$, evaluate their overall clinical status when deciding whether to transfuse.

\section{Fluids and electrolytes}

Fluid overload is associated with worse outcomes in severe CAP, particularly in those undergoing mechanical ventilation. ${ }^{[26-28]}$ Hyponatraemia is common secondary to high antidiuretic hormone secretion and is related to the severity of infection, ${ }^{[29-33]}$ but is less likely with isotonic intravenous manintenance fluids. ${ }^{[34]}$

Generally, children should be fed enterally; if this is not possible, then intravenous isotonic fluids should be administered at $<80 \%$ of maintenance, with monitoring of sodium levels.

\section{Antipyretics and analgesia}

Hospitalised children with pneumonia, who often have fever and may have chest pain, should receive treatment, ${ }^{[35,36]}$ including: ${ }^{[37]}$

- paracetamol, orally (loading dose $20 \mathrm{mg} / \mathrm{kg} / \mathrm{dose}$, then $15 \mathrm{mg} / \mathrm{kg} / \mathrm{dose}$ 4 - 6-hourly)

- ibuprofen, orally (10 mg/kg/dose 8-hourly) with meals

- where an anti-inflammatory effect is required

- can be used in combination with paracetamol or opioids

- tilidine (1 drop per $2.5 \mathrm{~kg}$ body weight, i.e. $1 \mathrm{mg} / \mathrm{kg} / \mathrm{dose}$ )

- intermediate-efficacy opioid.

\section{Other measures}

Over-the-counter cough medications are not effective in the management of CAP (evidence level Ia). ${ }^{[38]}$

Chest physiotherapy may be of benefit for children with lobar collapse, ${ }^{[39]}$ or when used in conjunction with nebulisation; ${ }^{[40]}$ however, routine chest physiotherapy is not recommended (evidence level Ia). ${ }^{[41,42]}$

Vaccination status should be reviewed and catch-up provided, including booster immunisation, as indicated.

\section{Summary: Treatment of pneumonia - supportive measures}

1. Children with room air oxygen saturations of $<92 \%$ (at sea level) or $<90 \%$ (at altitude $\geq 1800 \mathrm{~m}$ ) should be treated with oxygen (evidence level II)

2. Most children may receive oxygen via nasal cannula, but the route of oxygen administration should be individualised (evidence level IVa).
3. Children who are haemodynamically stable should not be transfused if their $\mathrm{Hb}$ is $\geq 7 \mathrm{~g} / \mathrm{dL}$ (evidence level II).

4. Children should be fed enterally; if this is not possible, administer intravenous isotonic fluids at $<80 \%$ of maintenance with monitoring of sodium levels (evidence level Ib/II).

5. Children with fever or chest pain should be treated with appropriate antipyretics or analgesics (evidence level IVa).

6. Over-the-counter cough medications are not recommended (evidence level Ia).

7. Chest physiotherapy may benefit children with lobar collapse (evidence level Ia)

8. Vaccination status should be reviewed and catch-up provided, including booster immunisation, as indicated (evidence level $\mathrm{IVb})$.

\section{Care of the child with pneumonia in the paediatric intensive care or high- care unit \\ Introduction}

A proportion of hospitalised children with CAP require admission to high care or the paediatric ICU (PICU); many of them have comorbid disease or other underlying susceptibilities.

\section{Admission criteria}

Specific criteria for PICU admission depend on available resources and vary between institutions (Table 3 ).

\section{Investigations \\ Microbiology}

See 'Epidemiology and aetiology of community-acquired pneumonia in children: South African Thoracic Society guidelines (part 1) ${ }^{5[46]}$ and 'Diagnosis of community-acquired pneumonia in children: South African Thoracic Society guidelines (part 2), $\cdot^{[47]}$

\section{Radiological investigations}

Radiological investigations should be individualised to evaluate for complications (e.g. pleural effusion, pneumothorax or segmental/lobar collapse), and associated cardiac disease. CXR or point-of-care chest ultrasound, where available, is recommended on admission to the PICU to define central line positioning, following endotracheal intubation, or with any significant deterioration. ${ }^{[48]}$

\section{Oxygen therapy and monitoring}

Clinical signs are inadequate for detecting hypoxia; ${ }^{[49]}$ therefore, continuous pulse oximetry monitoring is required.

\section{Respiratory support}

High-flow oxygen

See above: General and supportive measues: Respiratory support.

\section{Table 2. Criteria for discharge from hospital ${ }^{\star}$}

- Clinical improvement, indicated by improved activity, appetite, and resolution of fever for at least 12 hours. Do not discharge if increased work of breathing or tachycardia

- Pulse oximetry measurements consistently $\geq 90 \%$ at altitude ( $\geq 1800 \mathrm{~m}$ ) or $\geq 92 \%$ at sea level in room air for at least 12 hours

- Stable and/or return to baseline mental status

- If a chest tube was placed, no intrathoracic air leak for at least 12 - 24 hours after removal of the tube

- Ability to administer antibiotics at home, and child able to tolerate oral feeding and antibiotics

- Acceptable home circumstances and ability to return to hospital if clinical deterioration

${ }^{*}$ Adapted from the Pediatric Infectious Diseases Society and the Infectious Diseases Society of America guidelines. ${ }^{20}$ 
Table 3. Indications for paediatric intensive care unit admission

- Rapidly deteriorating clinical condition despite appropriate management

- Need for respiratory support as evidenced by

- apnoea (particularly in small infants)

- increasing oxygen requirements, i.e. any child requiring $\mathrm{FiO}_{2}>60 \%$ to maintain arterial saturations $>88 \%{ }^{[43-45]}$

- increasing effort of breathing (as assessed by respiratory rate, chest-wall retractions, noisy breathing), with imminent respiratory collapse

- hypercarbia resulting in respiratory acidosis

- Deterioration in level of consciousness or seizures, particularly if any concern about maintaining airway patency and avoiding aspiration

- Cardiovascular instability as reflected by severe tachycardia/hypotension/inotrope requirement

\section{Nasal continuous positive airway pressure systems}

nCPAP use for children with severe pneumonia (including bronchiolitis) is increasing as evidence emerges that supports its safety and efficacy. ${ }^{[50-54]}$

\section{Invasive ventilation}

Invasive ventilation is best provided in units experienced in such care, but often needs to be initiated prior to referral. High-frequency oscillatory ventilation may be considered for children requiring high mean airway pressure (MAP) using conventional ventilation. ${ }^{[55]}$

Children with significant airflow obstruction or hypercapnia require special consideration. Higher positive end-expiratory pressure (PEEP) and MAP may be required for children with refractory hypoxia (evidence level II). ${ }^{[56]}$

\section{Nutrition}

Critically ill children should be provided with enteral nutrition as soon as possible (evidence level Ib). ${ }^{[77,58]}$

Many ventilated children receive inadequate dietary intake, and provision of a higher proportion of prescribed dietary goals is associated with improved outcomes. ${ }^{[59]}$ Parenteral nutrition administration is associated with higher mortality and increased complications (evidence level Ib). ${ }^{[59-61]}$

Children on HFHNO or non-invasive positive-pressure ventilation may receive enteral feeding without risk of aspiration. ${ }^{[62,63]}$

\section{Antibiotic therapy}

While PICU-specific issues should be considered, the principles of antibiotic therapy are similar as for other children with CAP. Consider broader antimicrobial therapy for children whose clinical status worsens despite initial empiric therapy. Therapy should be de-escalated based on microbiology investigations. Extrapolating from adult ICU evidence, procalcitonin levels may guide discontinuation of antibiotics, ${ }^{[64]}$ although there are limited paediatric data. ${ }^{[65]}$

\section{Corticosteroids, fluid and blood transfusion}

These should be administered as per children with CAP managed outside of the ICU (see above: Adjunctive therapies: Corticosteroid therapy).

\section{Physiotherapy}

Current evidence is insufficient to provide strong recommendations for chest physiotherapy in the PICU. ${ }^{[6,67]}$

\section{Summary: High care and intensive care of children with pneumonia}

1. Where possible, blood cultures should be obtained from children requiring PICU admission, but should not delay initiation of antibiotic therapy (evidence level III).

2. CXR or chest ultrasound should be done to identify complications at PICU admission and after interventions, such as endotracheal intubation, chest drain or central line placement (evidence level III), and after clinical deterioration (evidence level III).

3. Oxygen saturation levels should be monitored continuously (evidence level IVa). Where possible, $\mathrm{FiO}_{2}$ should be adjusted to achieve saturations of $92-96 \%$ (evidence level III).

4. nCPAP improves outcomes compared with nasal cannula oxygen (evidence level $\mathrm{Ib}$ ), while nCPAP and HFHNO have similar efficacy in patients with severe bronchiolitis (evidence level Ib).

5. Antibiotic therapy should be de-escalated and discontinued as soon as possible (evidence level II).

6. Routine chest physiotherapy should not be provided for children (evidence level III), although some patients may benefit. Ongoing chest physiotherapy should be based on clinical improvement and lack of clinical deterioration (evidence level III).

\section{Special circumstances: HIV infection or exposure \\ Treatment}

Empiric CAP treatment of HIV-exposed uninfected (HEU) infants and HIV-infected children is the same as for HIV-unexposed children. There are currently no studies comparing regimens for and outcomes of HIV-infected and HEU infants. ${ }^{[68]}$ HIV infection should be considered in all children with CAP, and appropriate testing must be provided (evidence level IVa).

\section{Pneumocystis pneumonia}

Few children currently acquire vertically transmitted HIV infection most of these are diagnosed through early infant testing and receive antiretroviral therapy (ART) and co-trimoxazole prophylaxis. ${ }^{[69]}$ Women who tested HIV-negative during pregnancy may acquire HIV infection late in gestation or while breastfeeding - their infants are at risk of PCP (evidence level Ib). ${ }^{[70-73]}$ Some children with primary immunodeficiencies or severe malnutrition are also at risk of PCP (evidence level IIb). ${ }^{[74]}$ Empiric therapy for PCP should not be withheld pending results of confirmatory laboratory testing.

Co-trimoxazole administered intravenously or orally, $5 \mathrm{mg}$ trimetho$\mathrm{prim} / 25 \mathrm{mg}$ sulfamethoxazole $/ \mathrm{kg} /$ dose, 6-hourly for 21 days, reduces mortality from PCP in infants. ${ }^{[75]}$ Following treatment, daily co-trimoxazole prophylaxis needs to be continued until CD4+ counts recover as per South African (SA) ART guidelines. ${ }^{[76]}$ There is conflicting evidence regarding the effect of adjunctive corticosteroids. ${ }^{[77]}$ However, we recommend a short course of corticosteroids for children with PCP, initiated within 72 hours of diagnosis (prednisone 1 - $2 \mathrm{mg} / \mathrm{kg}$ orally daily for 7 days, tapered over the next 7 days) (evidence level IVa). ${ }^{[78]}$

\section{Cytomegalovirus}

Cytomegalovirus (CMV) pneumonia should be considered in HIVinfected or HEU infants $<6$ months of age with severe hypoxaemia or requiring mechanical ventilation. ${ }^{[79,80]}$ The optimal treatment remains unclear. Some clinicians initiate treatment if the whole-blood CMV 
viral load is $>4.1 \log _{10}$ copies $/ \mathrm{mL},{ }^{[81]}$ but this may delay therapy. Alternatively, initiate empiric ganciclovir and discontinue if CMV viral load results indicate low-level or absent viraemia (evidence level IVa).

In children with high-level CMV DNAemia, clinical improvement and/or a decline in viral load should prompt switching from intravenous ganciclovir to oral valganciclovir (evidence level IVa). Ganciclovir should be given at $5 \mathrm{mg} / \mathrm{kg}$ intravenously 12-hourly until oral therapy is tolerated, then switch to valganciclovir $16 \mathrm{mg} / \mathrm{kg}$ orally 12 -hourly until completion of 21 days of treatment. Thereafter, administer valganciclovir $16 \mathrm{mg} / \mathrm{kg}$ orally daily to complete a total of 42 days of therapy. ${ }^{[10}$

\section{Atypical organisms}

If 'atypical' organisms are considered in the differential diagnosis, a macrolide should be added (see above: Treatment of childhood pneumonia: Which empiric antibiotic?) (evidence level IVa).

\section{Summary: HIV infection or exposure}

Empiric antibiotic treatment is the same in HIV-infected, HEU and HIV-unexposed children, although treatment for PCP (evidence level Ib) and/or CMV pneumonia (evidence level IVa) should be considered in HIV-infected infants with severe hypoxaemia.

\section{Declaration. None.}

Acknowledgements. None.

Author contributions. The subgroup on treatment comprised ACA, TA, DPM, GR and HJZ. This group reviewed the evidence and wrote the manuscript. All authors reviewed and contributed to the final manuscript. Funding. HJZ and SAM are supported by the South African Medical Research Council.

Conflicts of interest. None.

1. Tramper-Stranders GA. Childhood community-acquired pneumonia: A review of etiology and antimicrobial treatment studies. Paediatr Respir Rev 2018;26:41-48. https://doi.org/10.1016/. prrv.2017.06.013

World Health Organization. Revised WHO Classification and Treatment of Pneumonia in Children at Health Facilities: Evidence Summaries. Geneva: WHO, 2014,

3. Von Gottberg A, de Gouveia L, Tempia S, et al. Effects of vaccination on invasive pneumococcal disease in South Africa. N Engl J Med 2014;371(20):1889-1899. https://doi.org/10.1056/NEJMoal401914

4. Moore DP, Baillie VL, Mudau A, et al The etiology of pneumonia in HIV-uninfected South Africa children: Findings from the Pneumonia Etiology Research for Child Health (PERCH) study. Pediat Infect Dis J 2020 (in press).

5. Moore DP, Baillie VL, Mudau A, et al. The etiology of pneumonia in HIV-1-infected South Africa Moore DP, Baillie VL, Mudau A, et al. The etiology of pneumonia in HIV-1-infected South African
children: Findings from the Pneumonia Etiology Research for Child Health (PERCH) study. Pediatr Infect Dis J 2020 (in press).

6. Lorgelly PK, Atkinson M, Lakhanpaul M, et al. Oral versus IV antibiotics for community-acquired pneumonia in children: A cost-minimisation analysis. Eur Respir J 2010;35(4):858-864, https://doi proumonia in children: A cost-

7. Nascimento-Carvalho CM. Community-acquired pneumonia among children: The latest evidence for an updated management. J Pediatr (Rio J) 2020;96(Suppl 1):29-38. https://doi.org/10.1016/j. jped.2019.08.003

. American Academy of Pediatrics. Red Book: 2018 Report of the Committee on Infectious Diseases. 31st ed. Elk Grove Village, IL: AAP, 2018

9. Mathur S, Fuchs A, Bielicki J, van den Anker J, Sharland M. Antibiotic use for communityacquired pneumonia in neonates and children: WHO evidence review. Paediatr Int Child Health 2018;38(Suppl 1):S66-S75. https://doi.org/10.1080/20469047.2017.1409455

10. National Department of Health. Standard Treatment Guidelines and Essential Medicines List for South African Hospital Level Paediatrics. Pretoria: $\mathrm{NDoH}, 2017$.

11. Stern A, Skalsky K, Avni T, Carrara E, Leibovici L, Paul M. Corticosteroids for pneumonia. Cochrane Database Syst Rev 2017;(12):CD007720. https://doi.org/10.1002/14651858.CD007720.pub3

12. Goussard P, Gie R. Airway involvement in pulmonary tuberculosis. Paediatr Respir Rev 2007;8(2):118-123 https://doi.org/10.1016/.jprrv.2007.04.007

13. Hussey GD, Klein M. A randomized, controlled trial of vitamin A in children with severe measles. N Engl J Med 1990;323(3):160-164. https://doi.org/10.1056/NEJM199007193230304

14. Kirkwood BR, Gove S, Rogers S, Lob-Levyt J, Arthur P, Campbell H. Potential interventions for the prevention of childhood pneumonia in developing countries: A systematic review. Bull World Health Organ 1995;73(6):793-798

5. Mehta S, Fawzi W. Effects of vitamins, including vitamin A, on HIV/AIDS patients. Vitamin Hormon 2007;75:355-383. https://doi.org/10.1016/s0083-6729(06)75013-0

6. Li W, Guo L, Li H, et al. Polymorphism rs2239185 in vitamin D receptor gene is associated with severe community-acquired pneumonia of children in Chinese Han population: A case-control study. Eur J Paediat 2015;174(5):621-629. https://doi.org/10.1007/s00431-014-2433-0

17. Esposito S, Lelii M. Vitamin D and respiratory tract infections in childhood. BMC Infect Dis 2015;15:487. https://doi.org/10.1186/s12879-015-1196-1
18. Somnath SH, Biswal N, Chandrasekaran V, Jagadisan B, Bobby Z. Therapeutic effect of vitamin D acute lower respiratory infection: A randomized controlled trial. Clin Nutr ESPEN 2017;20:24-28. https://doi.org/10.1016/i.clnesp.2017.02.003

19. Das RR, Singh M, Naik SS. Vitamin D as an adjunct to antibiotics for the treatment of acute childhood pneumonia. Cochrane Database Syst Rev 2018;(7):CD011597. https://doi.org/10.1002/14651858. D011597.pub2

20. Bradley JS, Byington CL, Shah SS, et al. The management of community-acquired pneumonia in infants and children older than 3 months of age: Clinical practice guidelines by the Pediatric Infectious Diseases Society and the Infectious Diseases Society of America. Clin Infect Dis 2011;53(7):25-76. https://doi.org/10.1093/cid/cir531

21. Smyth A, Carty H, Hart CA. Clinical predictors of hypoxaemia in children with pneumonia. Ann Trop Paediatr 1998;18(1):31-40.

22. Gie R, Madhi SA, Jeena P, Argent A, Zar HJ. Diagnosis and management of community-acquired pneumonia in childhood - South African Thoracic Society guidelines: Clinical guideline. South Afr J Epidemiol Infect 2009;24(1):25-36

23. Coletti KD, Bagdure DN, Walker LK, Remy KE, Custer JW. High-flow nasal cannula utilization in pediatric critical care. Respir Care 2017;62(8):1023-1029. https://doi.org/10.4187/respcare.05153

24. Davison M, Watson M, Wockner L, Kinnear F. Paediatric high-flow nasal cannula therapy in children with bronchiolitis: A retrospective safety and efficacy study in a non-tertiary environment. Emerg Med Austr 2017;29(2):198-203. https://doi.org/10.1111/1742-6723.12741

25. Bressan S, Balzani M, Krauss B, Pettenazzo A, Zanconato S, Baraldi E. High-flow nasal cannula oxygen for bronchiolitis in a pediatric ward: A pilot study. Eur J Paediatr 2013;172(12):1649-1656. https://doi. org/10.1007/s00431-013-2094-4

26. Lopes CLS, Piva JP. Fluid overload in children undergoing mechanical ventilation. Rev Brasil Terap Intens 2017;29(3):346-353. https://doi.org/10.5935/0103-507x.20170045

27. Ingelse SA, Wiegers HM, Calis JC, van Woensel JB, Bem RA. Early fluid overload prolongs mechanical ventilation in children with viral-lower respiratory tract disease. Pediatr Crit Care Med 2017;18(3):e106-el11. https://doi.org/10.1097/pcc.0000000000001060

28. Willson DF, Thomas NJ, Tamburro R, et al. The relationship of fluid administration to outcome in the pediatric calfactant in acute respiratory distress syndrome trial. Pediatr Crit Care Med 2013;14(7):666-672. https://doi.org/10.1097/PCC.0b013e3182917cb5

29. Tagarro A, Martin MD, Del-Amo N, et al. Hyponatremia in children with pneumonia rarely means SIADH. Paediatr Child Health 2018;23(7):e126-el33. https://doi.org/10.1093/pch/pxy003

30. Don M, Valerio G, Korppi M, Canciani M. Hyponatremia in pediatric community-acquired pneumonia. Pediatr Nephrol 2008;23(12):2247-2253. https://doi.org/10.1007/s00467-008-0910-2

31. Wrotek A, Jackowska T. Hyponatremia in children hospitalized due to pneumonia. Adv Exp Med Biol 2013;788:103-108. https://doi.org/10.1007/978-94-007-6627-3_16

32. Sakellaropoulou A, Hatzistilianou M, Eboriadou M, Athanasiadou-Piperopoulou F. Hyponatraemia in cases of children with pneumonia. Arch Med Sci 2010;6(4):578-583. https://doi.org/10.5114/ aoms.2010.14471

33. Shann F, Germer S. Hyponatraemia associated with pneumonia or bacterial meningitis. Arch Dis Child 1985;60(10):963-966

34. Ramanathan S, Kumar P, Mishra K, Dutta AK. Isotonic versus hypotonic parenteral maintenance fluids in very severe pneumonia. Ind J Pediatr 2016;83(1):27-32. https://doi.org/10.1007/s12098-015-1791-6

55. Fl-Radhi AS. Fever management: Evidence vs current practice. World I Clin Pediatr 2012;1(4):29-33. https://doi.org/10.5409/wjcp.v1.i4.29

36. Chiappini E, Venturini E, Remaschi G, et al. 2016 update of the Italian Pediatric Society guidelines for management of fever in children. J Pediatr 2017;180:177-183. https://doi.org/10.1016/j. jpeds.2016.09.043

37. Soda EA, Barskey AE, Shah PP, et al. Vital signs: Health care-associated Legionnaires' disease surveillance data from 20 states and a large metropolitan area - United States, 2015. MMWR Morbid Mortal Wkly Rep 2017;66(22):584-589. https://doi.org/10.15585/mmwr.mm6622e1

38. Chang $\mathrm{CC}$, Cheng $\mathrm{AC}$, Chang $\mathrm{AB}$. Over-the-counter (OTC) medications to reduce cough as an adjunct to antibiotics for acute pneumonia in children and adults. Cochrane Database Syst Rev 2014;(3):CD006088. https://doi.org/10.1002/14651858.CD006088.pub4

39. Warnock L, Gates A. Chest physiotherapy compared to no chest physiotherapy for cystic fibrosis. Cochrane Database Syst Rev 2015;(12):CD001401. https://doi.org/10.1002/14651858.CD001401.pub3

40. Lestari NE, Nurhaeni N, Chodidjah S. The combination of nebulization and chest physiotherapy improved respiratory status in children with pneumonia. Enferm Clin 2018;28(Suppl 1):19-22. https:// doi.org/10.1016/\$1130-8621(18)30029-9

41. Gilchrist FJ. Is the use of chest physiotherapy beneficial in children with community acquired pneumonia? Arch Dis Child 2008;93(2):176-178. https://doi.org/10.1136/adc.2007.127290

42. Damiani F, Adasme R. What is the effect of chest physiotherapy in hospitalized children with pneumonia? Medwave 2015;15(Suppl 2):e6287-e6287. https://doi.org/10.5867/medwave.2015.6287

43. World Health Organization. Oxygen Therapy for Children: A Manual for Health Workers. Geneva: WHO, 2016.

44. Kneyber MCI, de Luca D, Calderini E, et al. Recommendations for mechanical ventilation of critically ill children from the Paediatric Mechanical Ventilation Consensus Conference (PEMVECC). Intens Care Med 2017;43(12):1764-1780. https://doi.org/10.1007/s00134-017-4920-z

45. Harris M, Clark J, Coote N, et al. British Thoracic Society guidelines for the management of community acquired pneumonia in children: Update 2011. Thorax 2011;66(Suppl 2):iil-ii23. https://doi.org/10.1136/ horaxjnl-2011-200598

46. Moore DP, Green RJ, Cohen C, et al. Epidemiology and aetiology of community-acquired pneumonia in children: South African Thoracic Society guidelines (part 1). S Afr Med J 2020;110(7):583-587. https:// doi.org/10.7196/SAMJ.2020.v110i7.14997

47. Zar HJ, Moore DP, Itzikowitz G, et al. Diagnosis of community-acquired pneumonia in children: South African Thoracic Society guidelines (part 2). S Afr Med J 2020;110(7):588-593. https://doi.org/10.7196/ SAMJ.2020.v110i7.14998

48. Alonso-Quintela P, Oulego-Erroz I, Rodriguez-Blanco S, Muniz-Fontan M, Lapena-Lopez-de Armentia S, Rodriguez-Nunez A. Location of the central venous catheter tip with bedside ultrasound in young children: Can we eliminate the need for chest radiography? Pediatr Crit Care Med 2015;16(9):e340-e345. https://doi.org/10.1097/PCC.0000000000000491

49. Bassat Q, Lanaspa M, Machevo S, et al. Hypoxaemia in Mozambican children $<5$ years of age admitted Bassat Q, Lanaspa M, Machevo S, et al. Hypoxaemia in Mozambican children $<5$ years of age admitted
to hospital with clinical severe pneumonia: Clinical features and performance of predictor models. Trop Med Int Health 2016;21(9):1147-1156. https://doi.org/10.1111/tmi.12738

50. Jayashree M, KiranBabu HB, Singhi S, Nallasamy K. Use of nasal bubble CPAP in children with hypoxemic clinical pneumonia - report from a resource limited set-up. J Trop Pediatr 2016;62(1):69-74. https://doi.org/10.1093/tropej/fmv063

51. Machen HE, Mwanza ZV, Brown JK, et al. Outcomes of patients with respiratory distress treated with bubble CPAP on a pediatric ward in Malawi. J Trop Pediatr 2015;61(6):421-427. https://doi.org/10.1093/ tropej/fmv052

52. Milesi C, Essouri S, Pouyau R, et al. High flow nasal cannula (HFNC) versus nasal continuous positive airway pressure (nCPAP) for the initial respiratory management of acute viral bronchiolitis in young infants: A multicenter randomized controlled trial (TRAMONTANE study). Intens Care Med 2017;43(2):209-216. https://doi.org/10.1007/s00134-016-4617-8

53. Javouhey E, Barats A, Richard N, Stamm D, Floret D. Non-invasive ventilation as primary ventilatory support for infants with severe bronchiolitis. Intens Care Med 2008;34(9):1608-1614. https://doi. org/10.1007/s00134-008-1150-4 
54. Kawaguchi A, Yasui Y, deCaen A, Garros D. The clinical impact of heated humidified high-flow nasal cannula on pediatric respiratory distress. Pediatr Crit Care Med 2017;18(2):112-119. https://doi. nasal cannula on pediatric respiratory
$\mathrm{org} / 10.1097 / \mathrm{pcc} .0000000000000985$

55. Bateman ST, Borasino S, Asaro LA, et al. Early high-frequency oscillatory ventilation in pediatric acute respiratory failure. A propensity score analysis. Am J Resp Crit Care Med 2016;193(5):495-503. https:// doi.org/10.1164/rccm.201507-13810

56. Khemani RG, Parvathaneni K, Yehya N, Bhalla AK, Thomas NJ, Newth CJL. Positive end-expiratory pressure lower than the ARDS network protocol is associated with higher pediatric acute respiratory distress syndrome mortality. Am J Resp Crit Care Med 2018;198(1):77-89. https://doi.org/10.1164/ rccm.201707-1404OC

57. MikhailovTA, Kuhn EM, Manzi J, et al. Early enteral nutrition is associated with lower mortality in critically ill children. J Parenter Enteral Nutr 2014;38(4):459-466. https://doi.org/10.1177/0148607113517903

58. Wilson B, Typpo K. Nutrition: A primary therapy in pediatric acute respiratory distress syndrome. Front Pediatr 2016;4:108. https://doi.org/10.3389/fped.2016.00108

59. Mehta NM, Bechard LJ, Cahill N, et al. Nutritional practices and their relationship to clinical outcomes in critically ill children - an international multicenter cohort study. Crit Care Med 2012;40(7):2204-2211. https://doi.org/10.1097/CCM.0b013e31824e18a8

60. Fivez T, Kerklaan D, Mesotten D, et al. Early versus late parenteral nutrition in critically ill children. N Engl J Med 2016;374(12):1111-1122. https://doi.org/10.1056/NEJMoa1514762

61. Vanhorebeek I, Verbruggen S, Casaer MP, et al. Effect of early supplemental parenteral nutrition in the paediatric ICU: A preplanned observational study of post-randomisation treatments in the PEPaNIC trial. Lancet Respir Med 2017;5(6):475-483. https://doi.org/10.1016/s2213-2600(17)30186-8

62. Sochet AA, McGee JA, October TW. Oral nutrition in children with bronchiolitis on high-flow nasal cannula is well tolerated. Hosp Pediatr 2017;7(5):249-255. https://doi.org/10.1542/hpeds.2016-0131

63. Slain KN, Martinez-Schlurmann N, Shein SL, Stormorken A. Nutrition and high-flow nasal cannula respiratory support in children with bronchiolitis. Hosp Pediatr 2017;7(5):256-262. https://doi.org/10.1542/ hpeds.2016-0194

64. Schuetz P, Muller B, Christ-Crain M, et al. Procalcitonin to initiate or discontinue antibiotics in acute respiratory tract infections. Cochrane Rev J 2013;8(4):1297-1371. https://doi.org/10.1002/ebch.1927

65. Timsit JF, Bassetti $\mathrm{M}$, Cremer $\mathrm{O}$, et al. Rationalizing antimicrobial therapy in the ICU: A narrative review. Timsit JF, Bassetti M, Cremer O, et al. Rationalizing antimicrobial therapy in the ICU:
Intens Care Med 2019;45(2):172-189. https://doi.org/10.1007/s00134-019-05520-5

66. Morrow B. Chest Physiotherapy in the pediatric intensive care unit. J Pediatr Intens Care 2015;4:174-181

67. Corten L, Jelsma J, Morrow BM. Chest physiotherapy in children with acute bacterial pneumonia. S Afr J Physiother 2015;71(1):256. https://doi.org/10.4102/sajp.v71i1.256

68. Punpanich W, Groome M, Muhe L, Qazi SA, Madhi SA. Systematic review on the etiology and antibiotic treatment of pneumonia in human immunodeficiency virus-infected children. Pediatr Infect Dis J 2011;30(10):e192-e202. https://doi.org/10.1097/INF.0b013e31822d989c

69. Sherman GG, Mazanderani AH, Barron P, et al. Toward elimination of mother-to-child transmission of HIV in South Africa: How best to monitor early infant infections within the prevention of mother-tochild transmission program. J Glob Health 2017:7(1):010701. https://doi.org/10.7189/jogh.07.010701
70. Johnson LF, Stinson K, Newell ML, et al. The contribution of maternal HIV seroconversion during late pregnancy and breastfeeding to mother-to-child transmission of HIV. J Acquir Immune Defic Syndr pregnancy and breastfeeding to mother-to-child transmission of HIV. J
2012;59(4):417-425. https://doi.org/10.1097/QAI.0b013e3182432f27

71. Dinh TH, Delaney KP, Goga A, et al. Impact of maternal HIV seroconversion during pregnancy on early mother to child transmission of HIV (MTCT) measured at $4-8$ weeks postpartum in South Africa 2011 - 2012: A national population-based evaluation. PLoS ONE 2015;10(5):e0125525. https:/ doi.org/10.1371/journal.pone.012552

72. Dinh TH, Mushavi A, Shiraishi RW, et al. Impact of timing of antiretroviral treatment and birth weight on mother-to-child human immunodeficiency virus transmission: Findings from an 18-month prospective cohort of a nationally representative sample of mother-infant pairs during the transitio from option A to option B+ in Zimbabwe. Clin Infect Dis 2018;66(4):576-585. https://doi.org/10.1093/ cid/cix820

73. Tippett Barr BA, van Lettow M, van Oosterhout JJ, et al. National estimates and risk factors associated with early mother-to-child transmission of HIV after implementation of option B+: A cross-sectional analysis. Lancet HIV 2018;5(12):e688-e695. https://doi.org/10.1016/s2352-3018(18)30316-3

74. Avino LJ, Naylor SM, Roecker AM. Pneumocystis jirovecii pneumonia in the non-HIV-infected population. Ann Pharmacother 2016;50(8):673-679. https://doi.org/10.1177/1060028016650107

75. Chintu C, Bhat GJ, Walker AS, et al. Co-trimoxazole as prophylaxis against opportunistic infections in HIV-infected Zambian children (CHAP): A double-blind randomised placebo-controlled trial. Lancet HIV-infected Zambian children (CHAP): A double-blind randomised placebo-co

76. National Department of Health. 2019 ART Clinical Guidelines for the Management of HIV in Adults, National Department of Health. 2019 ART Clinical Guidelines for the Managem
Pregnancy, Adolescents, Children, Infants and Neonates. Pretoria: NDoH, 2019.

Pregnancy, Adolescents, Children, Infants and Neonates. Pretoria: $\mathrm{NDoH}, 2019$.
77. Terblanche AJ, Green RJ, Rheeder P, Wittenberg DF. Adjunctive corticosteroid treatment of clinical 77. Terblanche AJ, Green RJ, Rheeder P, Wittenberg DF. Adjunctive corticosteroid treatment of clinical
Pneumocystis jiroveci pneumonia in infants less than 18 months of age - a randomised controlled trial. Pneumocystis jiroveci pneumoni
S Afr Med J 2008;98(4):287-290

78. Newberry L, O'Hare B, Kennedy N, et al. Early use of corticosteroids in infants with a clinical diagnosi of Pneumocystis jiroveci pneumonia in Malawi: A double-blind, randomised clinical trial. Paediatr In Child Health 2017;37(2):121-128. https://doi.org/10.1080/20469047.2016.1260891

79. Goussard P, Kling S, Gie RP, et al. CMV pneumonia in HIV-infected ventilated infants. Pediatr Pulmono 2010;45(7):650-655. https://doi.org/10.1002/ppul.21228

80. Kitchin OP, Wessels F, Masekela R, Becker P, Green RJ. Costs of admission for paediatric pneumonia in a setting of human immunodeficiency virus infection. Int J Tuberc Lung Dis 2011:15(12):1702-1707. https://doi.org/10.5588/ijtld.11.0167

81. Hsiao NY, Zampoli M, Morrow B, Zar HJ, Hardie D. Cytomegalovirus viraemia in HIV exposed and infected infants: Prevalence and clinical utility for diagnosing CMV pneumonia. J Clin Virol 2013:58(1):74-78. https://doi.org/10.1016/j.jcy.2013.05.002

Accepted 10 June 2020. 